\title{
Breast reconstruction and radiation therapy: A Canadian perspective
}

\author{
Oluwatola O Afolabi MA MD, Donald H Lalonde MD MSc FRCSC, Jason G Williams MD FRCSC
}

\begin{abstract}
OO Afolabi, DH Lalonde, JG Williams. Breast reconstruction and radiation therapy: A Canadian perspective. Can J Plast Surg 2012;20(1):43-46.
\end{abstract}

BACKGROUND: When and how best to perform breast reconstruction in the setting of radiation therapy is a much debated topic.

OBJECTIVE: To investigate the approaches that Canadian plastic surgeons are taking to breast reconstruction in patients who require or may require radiation therapy.

METHODS: In April 2009, a survey invitation was sent to Canadian plastic surgeons via e-mail. Survey responses were collected over a two-month period.

RESULTS: Of the 307 invitees, 90 surgeons responded, of whom 76 met the inclusion criteria. Most surgeons (66\%) do not perform immediate reconstruction in patients who require postmastectomy radiation. Most respondents (64\%) perform immediate reconstructions for patients whose need for radiation is uncertain at the time of mastectomy. Expander and implants is their preferred option, followed by free transverse rectus abdominis myocutaneous (TRAM) flap. Thirty-five per cent use the delayed immediate technique in these cases. Twenty-one per cent are unfamiliar with the delayed-immediate technique. For delayed reconstruction of the irradiated patient, the pedicled TRAM is the most common choice.

CONCLUSIONS: The reconstructive options are increasing for patients who may need postmastectomy radiation. The use of the delayed immediate technique could increase as physicians gain more knowledge of the technique.

Key Words: Breast reconstruction; Clinical practice survey; Radiation therapy
$\mathbf{R}$ adiation therapy is increasingly used to treat breast cancer. Plastic R surgeons are, therefore, faced with the challenges of timing breast reconstruction in these patients. Postmastectomy radiation therapy is currently indicated for patients with T3 or stage III tumours, and those with four or greater positive axillary nodes $(1,2)$. However, the role of radiation therapy for patients with $\mathrm{T} 1$ and $\mathrm{T} 2$ tumours is being investigated in clinical trials, underscoring the rapidly evolving nature of this area of oncology (2).

Mastectomy followed by immediate reconstruction is a favourable option because the breast shape and skin envelope are maintained, resulting in a better aesthetic result $(3,4)$. However, postreconstruction radiation increases complications such as contracture and necrosis $(3,4)$. The risks are especially high when implants are chosen over native tissue $(5,6)$. Furthermore, the reconstructed breast may act as a mechanical barrier to adequate delivery of radiation to the inframammary nodes and result in unnecessary radiation of the lungs and the heart (6).

Reconstruction in a radiated tissue bed can also be difficult if skin flaps are not sufficiently pliable to stretch over implants. The skin flaps are also susceptible to necrosis (4). In this situation, autologous reconstruction has been shown to limit complication rates.

Particularly challenging is how to approach breast reconstruction in a patient whose need for radiation therapy is unknown at time of mastectomy. In these patients, weighing the benefits of immediate reconstruction against the risks of a reconstructed breast possibly receiving radiation mandates a well-thought-out treatment plan. The aim of the present study was to investigate the approaches that Canadian plastic surgeons are taking to this area of reconstruction.

\section{La reconstruction mammaire et la radiothérapie : une perspective canadienne}

HISTORIQUE : Le moment et la manière de procéder à une reconstruction mammaire en présence de radiothérapie constituent un sujet controversé. OBJECTIF : Explorer les approches qu'adoptent les plasticiens canadiens en matière de reconstruction mammaire chez les patientes qui ont besoin ou sont susceptibles d'avoir besoin de radiothérapie.

MÉTHODOLOGIE : En avril 2009, les chercheurs ont invité par courriel les plasticiens du Canada à participer à un sondage et ont colligé leurs réponses sur une période de deux mois.

RÉSULTATS : Quatre-vingt-dix chirurgiens ont répondu aux 307 invitations, et 76 respectaient les critères d'inclusion. La plupart des chirurgiens $(66 \%)$ ne procèdent pas à une reconstruction immédiate chez les patientes qui ont besoin d'une radiothérapie après une mastectomie. La plupart des répondants $(64 \%)$ procèdent toutefois à une reconstruction immédiate chez les patientes dont on ne connait pas les besoins en radiothérapie au moment de la mastectomie. Les expanseurs et les implants sont la solution favorisée, suivis d'un lambeau du grand droit abdominal. Trente-cinq pour cent utilisent alors la technique immédiate différée, mais $21 \%$ ne la connaissent pas. En cas de reconstruction différée des patientes irradiées, le lambeau du grand droit abdominal pédiculé est le choix le plus courant.

CONCLUSIONS : Les options de reconstruction augmentent pour les patientes qui peuvent avoir besoin d'une radiothérapie après une mastectomie. Le recours à la technique immédiate différée pourrait augmenter à mesure que les médecins la connaîtront mieux.

Division of Plastic and Reconstructive Surgery, Dalhousie University, Saint John, New Brunswick

Correspondence: Dr Donald H Lalonde, Division of Plastic and Reconstructive Surgery, Dalhousie University, Hilyard Place, Suite A280,

560 Main Street, Saint John, New Brunswick E2K 1J5. Telephone 506-648-7950, fax 506-652-8042, e-mail drdonlalonde@nb.aibn.com 


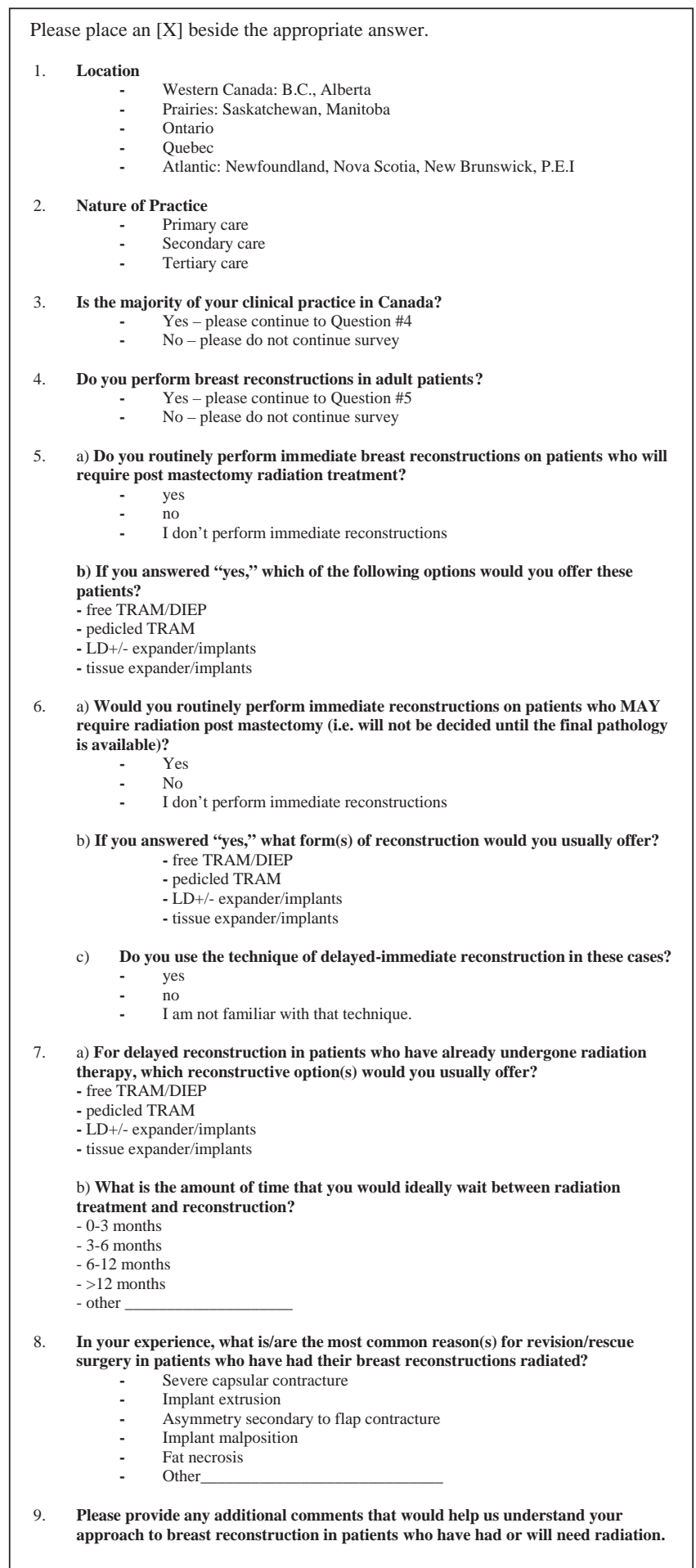

Figure 1) Postmastectomy reconstruction and radiation therapy clinical practice survey. BC British Columbia; DIEP Deep inferior epigastric perforator; LD Latissimus dorsi; PEI Prince Edward Island; TRAM Transverse rectus abdominis myocutaneous

Surgeons were excluded from the study if the majority of their practice was outside of Canada or if they did not perform breast reconstructions in adult patients.

\section{RESULTS}

Ninety plastic surgeons responded to the survey (29\% response rate), and 76 met the inclusion criteria. Five surgeons could not be reached via e-mail. The majority of surgeons practiced in Ontario
TABLE 1

Geographical distribution of survey respondents

\begin{tabular}{lc}
\hline Region & Surgeons, $\mathbf{n}(\%)$ \\
\hline Ontario & $26(34)$ \\
Western Canada & $25(33)$ \\
Atlantic Canada & $11(14)$ \\
Prairies & $8(10)$ \\
Quebec & $6(8)$ \\
\hline
\end{tabular}

and Western Canada (Table 1). There was near equal representation of both community (43\%) and academic (54\%) practice.

Scenario 1 . Do you routinely perform immediate breast reconstructions on patients who will require postmastectomy radiation treatment?

Most surgeons (66\%) did not perform any form of immediate reconstruction on patients who were known to require postmastectomy radiation therapy. Only $30 \%$ of surgeons $(n=23)$ performed immediate reconstruction in these patients. In this latter group of surgeons, prosthetic reconstruction was the most commonly offered option (Figure 2), followed by free TRAM, LD, then pedicled TRAM. Four per cent $(n=3)$ of surgeons do not perform immediate reconstruction for any patient requiring breast reconstruction.

Scenario 2 . Would you routinely perform immediate reconstructions on patients who MAY require radiation postmastectomy (ie, will not be decided until the final pathology is available)?

Thirty-four per cent $(n=26)$ of surgeons would not perform an immediate reconstruction for patients whose need for radiation was uncertain at the time of surgery, and 64\% ( $n=49)$ would. In the group that would operate, expander/implant reconstruction was the preferred option. This would be considered by 35 of the 49 physicians (71\%). Either pedicled $(43 \%)$ or free $(40 \%)$ TRAM would also be offered (Figure 3 ).

For this scenario, $35 \%$ of surgeons $(n=27)$ would use the delayedimmediate method of reconstruction. Forty-two per cent of surgeons $(n=32)$ would not use this method. A minority of physicians $(21 \%)$ were unfamiliar with delayed-immediate approach. One physician did not answer the question.

Scenario 3. For delayed reconstruction in patients who have already undergone radiation therapy, which reconstructive option(s) would you usually offer?

Pedicled TRAM was the most commonly offered option for breast reconstruction with $60 \%(n=45)$ of surgeons considering it (Figure 4$)$. LD and free TRAM were nearly equally popular, and were offered by $56 \%(n=42)$ and $52 \%(n=39)$ of surgeons, respectively. Expander/ implant reconstruction was less favoured for this group of patients only $36 \%(n=27)$ of surgeons presented it as a choice to patients.

The preferred wait time between radiation therapy and breast reconstruction was six to 12 months.

\section{DISCUSSION}

Breast reconstruction in the patient requiring radiation therapy There is substantial risk to the reconstructed breast undergoing radiation (7-10). In autologous reconstruction, flaps can shrink and develop contour abnormalities. Partial flap loss has also been noted. In a landmark study performed at the MD Anderson Centre (Texas, USA), patients who had radiation therapy following immediate breast reconstruction with free TRAM flaps demonstrated a significantly higher rate of late complications such as fat necrosis, volume loss and flap contracture than did those patients who received radiation therapy before free TRAM reconstruction (8). Twenty-eight per cent of the flaps required a second flap to address the consequences of radiation. Rogers and Allen (10) reported similar findings in DIEP flap breast 


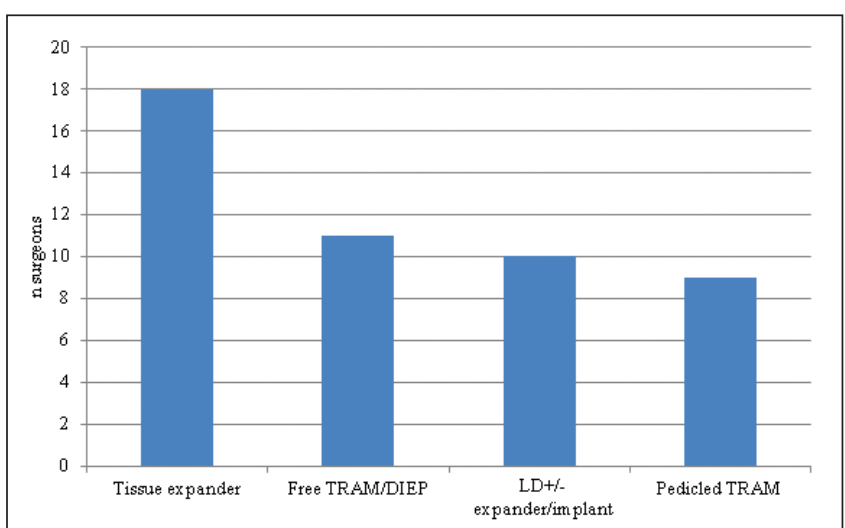

Figure 2) Reconstructive options offered to patients requireing radiation therapy. DIEP Deep inferior epigastric perforator; LD Latissimus dorsi; TRAM Transverse rectus abdominis myocutaneous

reconstruction. Reconstructed breasts subjected to radiation showed significantly higher rates of fat necrosis, fibrosis, shrinkage and contracture, as well as lower aesthetic scores when compared with nonradiated patients $(10)$.

Evans et al (9) reported a significantly increased risk of capsular contracture, complications, and need for implant removal in prosthetic reconstruction both before and after radiation therapy. Covering the implant with autogenous tissue did not change outcomes. Spear and Onyewu (11) made similar conclusions in their study of two-stage saline implant reconstruction in radiated patients. Complications were more common in the radiated group, with the latter demonstrating a $32.5 \%$ capsular contracture rate, whereas there were no contractures in the nonradiated group (11). They reported that covering the implant with an LD flap was protective. Nonetheless, 19 of 40 patients $(47.5 \%)$ required flap salvage compared with $10 \%$ of patients in the nonradiated group.

Although there are several reports of successful immediate reconstructions that have been irradiated, this seems to be the exception and not the rule. It is, therefore, reasonable that the majority of physicians surveyed in the present study would not offer immediate reconstruction to patients requiring radiation. For the minority of physicians who would offer immediate reconstruction to such patients, prosthetic reconstruction was a favoured option. This may be due to the relative ease and convenience of prosthetic reconstruction in comparison with autogenous reconstruction. Notably, however, the second most commonly offered choice was robust autogenous reconstruction in the form of a free TRAM flap. Free flaps have been shown to better withstand the effects of radiation than prosthetic reconstruction $(12,13)$. Although revision surgery may be needed, the reconstruction can often be salvaged.

Reconstruction of the patient who may require radiation and the role of the delayed-immediate technique

Nearly one-half (46\%) of surgeons would offer prosthetic reconstruction to patients whose need for radiation was unknown at the time of surgery. Possible explanations were provided by physician comments in the freetext section of the survey. Several surgeons noted that they used the implants either as a final reconstruction method or as a skin envelope preserver while the patient awaited the final pathology result. Another surgeon commented that using a prosthesis allows the patient more time to consider her reconstructive options and perhaps proceed to autologous reconstruction after receiving the pathology result.

Regardless of the indications, the delayed-immediate reconstruction method of placing an expander temporarily at the time of mastectomy has been described by Kronowitz et al (14). In a 2004 study, the MD Anderson group presented this as a means of preserving the skin envelope until final pathology results of the breast specimen and lymph node biopsy were available. In the first stage, a tissue expander

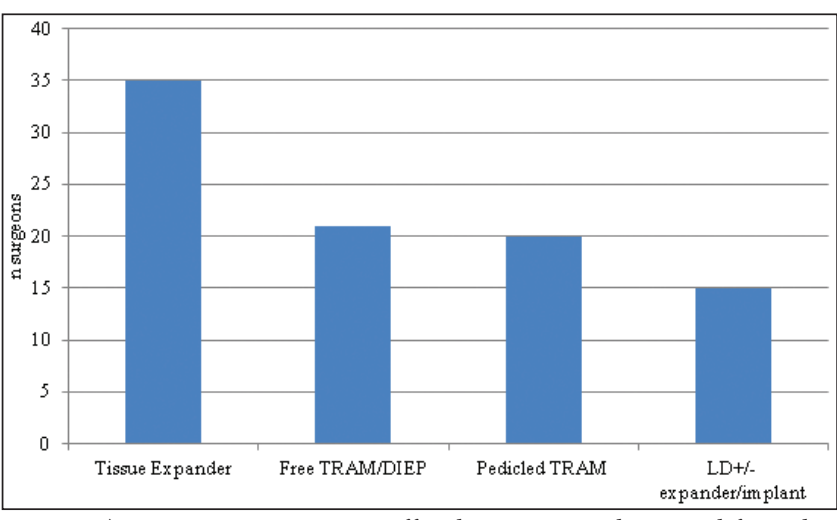

Figure 3) Reconstructive options offered to patients whose need for radiation therapy is unknown at time of mastectomy. DIEP Deep inferior epigastric perforator; LD Latissimus dorsi; TRAM Transverse rectus abdominis myocutaneous

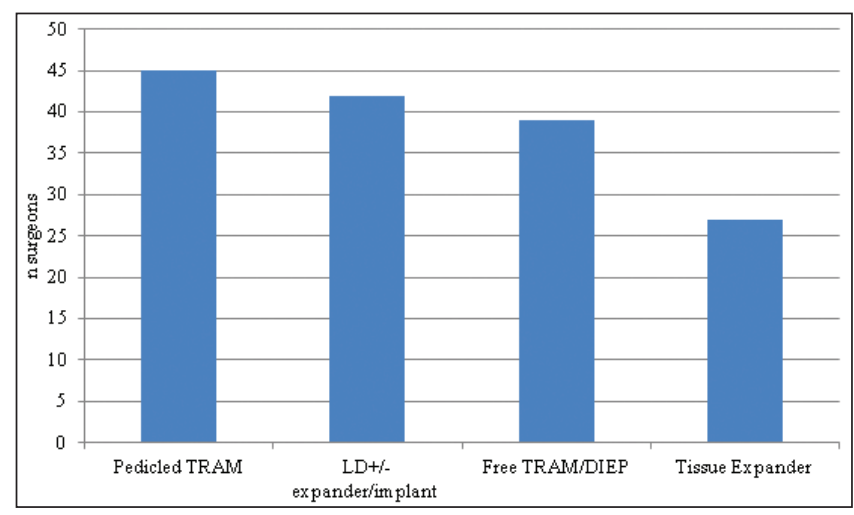

Figure 4) Delayed reconstructive options offered to patients who have received radiation. DIEP Deep inferior epigastric perforator; LD Latissimus dorsi; TRAM Transverse rectus abdominis myocutaneous

is placed submuscularly and filled to maximum volume at the time of the skin-sparing mastectomy $(14,15)$. Final pathology is reviewed and the second stage occurs two weeks later. If radiation therapy is not indicated, the expanders are removed, the flaps and tissue are debrided as needed and definitive breast reconstruction is performed with either TRAM, superior gluteal artery perforator flap, LD with implants, or implants alone. If radiation is indicated, the expander is deflated before its administration to enable the best access to inframammary nodes and limit collateral damage to the lungs and the heart. Re-expansion is then performed after the completion of radiation therapy. Delayed reconstruction in the form of TRAM, superior gluteal artery perforator flap or LD with implants is then performed.

Kronowitz et al (14) reported success in nine patients who underwent both stages. Complications ranged from site seroma to microvascular thrombosis; however, no flap losses occurred.

Although the delayed-immediate technique is a relatively new approach, more than two-thirds of polled physicians were familiar with it. That more than $30 \%$ of surgeons would use it when applicable speaks of its acceptability as a means of preserving the benefits of immediate reconstruction without jeopardizing the aesthetic results via a radiated reconstruction.

Breast reconstruction in the patient who has received radiation therapy

Our survey surgeons expressed a strong preference for autologous reconstruction such as the TRAM flap for the patient with a radiated mastectomy site. This is consistent with recommendations presented in the literature (15). Several studies have noted fewer complications in TRAM reconstructions and concluded that the flap brought healthy tissue with reparative capabilities to a compromised wound 
bed $(12,13)$. Favouring a pedicled TRAM or an LD with implants over a free tissue transfer may be largely due to the relative ease of performing these surgeries. In addition, radiated recipient vessels are sometimes a problem. Temple et al (16) reported that 17 of 123 planned free TRAMs were converted to pedicled TRAMs because of unusable internal mammary artery recipient vessels in radiated patients (16).

A wait time of six to 12 months postradiation therapy was preferred by the surgeons in our study. Baumann et al (17) studied radiationrelated complications in abdominal breast reconstructions, and reported that delayed reconstructions performed 12 months after radiation therapy had a significantly lower risk of reoperation rates for microvascular compromise as well as flap loss compared with reconstructions performed earlier than 12 months after radiation therapy.

\section{Limitations}

The present study was limited by its low response rate of $29 \%$. However, many Canadian plastic surgeons do not perform breast reconstructions and would, therefore, not respond.

\section{CONCLUSION}

The results of the survey indicate that Canadian physicians are largely informed by the results in the literature. The deviations seen in the form of favouring prosthetic reconstruction may be due, in part, to the relative ease and convenience of this option as well as the ability to allow the surgeon to later proceed with autologous reconstruction if decided by the patient. The varied approaches presented underscore the complexity of approaching breast reconstruction in a patient requiring radiation therapy.

DISCLOSURES: The authors have no financial disclosures or conflicts of interst to declare.

\section{REFERENCES}

1. Recht A, Edge SB, Solin LJ, et al. Postmastectomy radiotherapy: Guidelines of the American Society of Clinical Oncology. J Clin Oncol 2001;19:1539-69.

2. Lee M, Jagsi M. Postmastecomy radiation therapy: Indications and controversies. Surg Clin N Am 2007;85:511-26.
3. Ananthakrishnan P, Lucas A. Options and considerations in the timing of breast reconstruction after mastectomy. Cleve Clin J Med 2008;75:S30-3.

4. Sigurdson L, Lalonde DH. MOC-PS CME Article: Breast reconstruction. Plast Reconstr Surg 2008;121:1-12.

5. Ahmed S, Snelling A, Bains M, Whitworth IH. Breast reconstruction. BMJ 2005;330:943-8.

6. Senkus-Konefca E, Welnicka-Jaskiewicz M, Jaskiewicz J, Jassem J. Radiotherapy for breast cancer in patients undergoing breast reconstruction or augmentation. Cancer Treat Rev 2004;30:671-82.

7. Behranwala KA, Dua RS, Ross GM, Ward A, A'hern R, Gui GP. The influence of radiotherapy on capsule formation and aesthetic outcome after immediate breast reconstruction using biodimensional anatomical expander implants. J Plast Reconstr Aesthet Surg 2006;59:1043-51.

8. Tran NV, Chang DW, Gupta A, Kroll SS, Robb GL. Comparison of immediate and delayed free TRAM flap breast reconstruction in patients receiving postmastectomy radiation therapy. Plast Reconstr Surg 2001;108:78-82.

9. Evans GR, Schusterman MA, Kroll SS, et al. Reconstruction and the radiated breast: Is there a role for implants? Plast Reconstr Surg 1995;96:1111-5.

10. Rogers NE, Allen RJ. Radiation effects on breast reconstruction with the deep inferior epigastric perforator flap. Plast Reconstr Surg 2002;109:1920-4.

11. Spear SL, Onyewu C. Staged breast reconstruction with saline-filled implants in the irradiated breast: Recent trends and therapeutic implications. Plast Reconstr Surg 2000;105:930-41.

12. Wong JS, Ho AY, Kaelin CM, et al. Incidence of major corrective surgery after post-mastectomy breast reconstruction and radiation therapy. Breast J 2007;14:46-54.

13. Kronowitz SJ, Robb GL. Radiation therapy and breast reconstruction: A critical review of the literature. Plast Reconstr Surg 2009;124:395-408.

14. Kronowitz SJ, Hunt KK, Kuerer HM, et al. Delayed-immediate breast reconstruction. Plast Reconstr Surg 2004;113:1618-28.

15. Kronowitz SJ. Delayed-immediate breast reconstruction: Technical and timing considerations. Plast Reconstr Surg 2010;125:463-74.

16. Temple CL, Strom EA, Youssef A, Langstein HN. Choice of recipient vessels in delayed TRAM flap breast reconstruction after radiotherapy. Plast Reconstr Surg 2005;115:105-13.

17. Baumann DP, Crosby MA, Selber JC, et al. Optimal timing of delayed free lower abdominal flap breast reconstruction after postmastectomy radiation therapy. Plast Reconstr Surg 2011;127:1100-6. 